\title{
Paradigms Found: Phronesis and Pragmatic Humanism for International and Domestic NGOs
}

\author{
Douglas K. Peterson, $\mathrm{PhD}$ \\ Business without Borders, the NGO/NPO Institute, Incorporated \\ $610134^{\text {th }}$ St. West, Suite 4 H, Bradenton, Florida 34210 \\ Tel: 1-941-567-4121 E-mail:Peterson@business-without-borders.org
}

\begin{abstract}
In the theory surrounding the management of non-governmental organizations (NGOs) there seems to be a lack of what Aristotle would call sophia, phronesis, and eudaimonia (as found in the Nicomachian Ethics). In plain terms, these are the wisdom, practicality and desired outcomes for theory and practice as evidenced by the lack of a coherent structure, or set of paradigms, for structuring wisdom and offering the explanation of phenomena as well as prediction of why or when those phenomena will happen. This paper is on the development of paradigms related to the understanding and management of international NGOs and their population, management and membership. The intention of paper is upon structuring arguments from interpretive, radical structuralist, radical humanist and functionalist paradigms into a pragmatic humanism that hasn't been introduced in the management, NGO, or public administration literature.
\end{abstract}

Keywords: Management, International NGO, Pragmatic Humanism, Paradigm Development, Phronesis

\section{Introduction}

In the public administration and management literature there's not a great deal on the development of paradigmatic pragmatic wisdom and practical outcomes that is of direct use in our understanding of the rise of the non-governmental organization (NGO) and the lack of trust in governments and corporations as places to work. This paper is on the management of non-governmental organizations, or NGOs, whose organizational purpose and definition is to enact a domestic or international social movement that government or business institutions have not enacted (Teegen, Doh, and Vachani, 2004). Further, growing lack of trust of business and governmental organizations brings the salience of the NGO into view. Currently, NGOs are more integrated, organized, and influential in the global environment than ever before and academics need some direction in explaining their actions, predicting their behavior and offering pragmatic wisdom, or a phronesis, for future academic theory and practical action. This paper attempts to thoroughly explore the concepts of paradigm development while building the concept of practical humanism onto Burrell and Morgan's (1979) orthogonal representation of structuralism, functionalism, radical humanism and radical structuralism. There is nothing like this paper in the management or NGO-related literature, so to that end; it is completely original.

\section{Paradigms}

Thomas Kuhn (1970), in The Structure of Scientific Revolutions explains the development of dominant paradigms within academic fields. In it, a field looks to be in a situation that Kuhn (1970) would call "pre-paradigmatic" when there is little agreement on major research themes, methods, training or even quality assurance. In other words, this is the place in which a field of understanding exists before the creation of "normal science" where methods, understanding of direction in the field, training and production efforts are not yet agreed upon. Were they in agreement, it would lead to the state of which would signify "normal science" where a lack of understanding or agreement is called "abnormal science". Conceptually, the philosophical move from abnormal science to normal science requires time and growing disharmony. An area of endeavor is not immune to the movement from normal science to abnormal science depending upon practical constructions, agreement in the field, and the social structure in control of a preponderance of agendas. This oscillation often occurs in a timeframe of years, the examples being the development of stability in chemistry, mathematics, and physics which all used centuries to establish "normal science". As young fields, management - or even public administration - has yet to thoroughly establish paradigmatic agreement that establishes them as a profession where there is an agreed curriculum and training that resembles a pragmatic residency.

In pragmatic and academic terms, the management disciplines do have their dominant paradigms, none of which are without criticism and the oscillation from empiricism to structuralism, contingency, operations research, processualism, or multi-trait and multi method research which indicates this field is still trying to find its roots. One criticism is that while they management research produces useful knowledge and understanding, it is are responsible for helping to limit training, research foci, and priorities within the field (Kuhn, 1970; Pfeffer, 1993; Hassard and 
Parker, 1993). They are not included in the mainstream, however if they come to the mainstream, decisions about how long they exist come naturally as agendas change. One argument is this has the effect of creating limits on discourse where one might argue that the use of one or a small number of paradigms produces a view that neglects a multidisciplinary and multifaceted nature of organizational understanding. This produces a Kuhnian crisis of faux incommensurability that prohibits theoretical advancement and combination of work (Dando and Bennett, 1981). This creates the need to trim the garden of general understandings while also creating the need for dialogue between factions or dominant players.

This particular work is also about the way we understand research and phenomenology as it relates to the work and the rise of the NGO. In this paper's opinion there is not enough research on the NGO, the people who work there and the operational details of the entities. We understand NGOs and we see they operate effectively in most cases. What is needed is the basic research and the cases that help us to train NGO managers while creating theory that explains, predicts and controls the phenomenology surrounding the organization and allowing for the contribution to the practical success of these organizations. Also, there is not enough literature, perhaps a few dozen articles on academic or pragmatic topics, and we could use more. To characterize the literature, most NGO material presents area studies, like NGOs in Africa or Asia; policy advice (Kim, 2009; Yarrow, 2008; Guinn, 2008); and managerial direction based largely on organization direction and policy (Uvjn and Jain, 2000). There are also some adventures into foundation money and how to get it (Fowler, 2008).

In paradigm research for the $\mathrm{NGO}$ we have a relatively new field of inquiry. It is a new and even virtual organizational form. We need to understand the population of NGOs and how it changes; the management of NGOs and how it is different and how it is the same as management in the organizational literature; and finally we need to understand the membership of NGOs and why people volunteer their time or work for them as opposed to a potentially more lucrative choice. This population, membership and management (PMM) is a very large portion of the research agenda being created. There are new understandings for funding bases and continuing disagreement as to whether our understandings should be policy oriented or more practically placed into management, operations, government, or supra-governmental organizations (like the UN). By placing NGO research into the policy oriented literature we generally use only some of our understanding; we can introduce more in the effort to explain, predict, and control this phenomenology.

Existing paradigms in management, the social sciences, and the humanities may not adequately explain the practical phenomenology and wisdom of the NGO and its operations. We can perhaps overcome the limitation of additional discourse by examining other thought patterns that may shed light on matters of governance and commensurability of working with business organizations effectively. We can then open the field more broadly to scholars, teachers, students, and practitioners who would provide creativity in their work inside or outside of a main stream.

In the presentation of this paper, pragmatic humanism will be compared with alternatives ranging from radical humanism, radical structuralism, functionalism, and interpretive patterns. This allows for better and more productive partnerships between human service missions while enhancing the mutual understanding between business and NGO organizations. Gioia cleverly coined the term "paradigm lost" (1993), you might call this paper a "paradigm found". It provides the sophia (wisdom), the eudaimonia (desired end) and the phronesis (practical wisdom) of discourse from which to address the critical issues facing NGOs. For reference, Sophia, eudaimonia and phronesis are from Aristotle's Nicomachean Ethics.

\section{Pragmatic Humanism}

Pragmatic humanism gives persons, and in this case managers, professionals, or NGO workers or managers the means to be active agents in the construction of their own existence. The meaning of this statement is that there is an epistemological dominance or nature of organizational and governmental development in management surrounding person's work. Let us explore that epistemology and see if we can develop our understanding of the pragmatic humanism in Faucault (1997), or Reynolds (2004).

As previously mentioned, the nature of normal science is where an academic discipline agrees on methods, training, subjects, and approaches to prescribed problems of interest. In short, everyone should be on the same page. There is a pragmatic enforcement of anthropological normal science through the norms, mores and folkways that establish that mechanism. An example can be the norm for picking member of boards of directors/advisors in corporations and governmental organizations. This is done through an epistemological structure and has the effect of keeping organization and organization structure and practice within the concept of normal science. This epistemological framework, one that governs through rules and through institutions purports to admire and support freedom, however in reality it acts as a "psychic prison" or "iron cage" from which normal science is maintained.

Pragmatic humanism somewhat is difficult to approach so it's best to split the concept into the pragmatism of 
Faucault (1997) and the humanism of both Dewey (1931) and Faucault (1997). According to the pragmatic humanism of Faucault (1997) there is a struggle against the epistemological along which power is said to be formed. In response, people productively engage in practices of self invention as positive forms of resistance and take refuge in the language of an embodied, political and ultimately pragmatic humanism. Also, there exists a citizenship that has its rights and its duties and which holds an obligation to speak out against abuses of power. In appropriating these themes, this earlier Foucault would say we can no longer think in terms of the rational progress of humanity and can no longer longer subject to the epistemological tyranny with their arbitrary insistence on the primacy of practices residing in a finite cognito. Humanism is reconfigured as an Enlightenment driven desire to realize both individual freedom and the freedom of others and as such seeks the freedom of the epistemological (perhaps through joining or starting an NGO) without buying into the modern mode of subordination. Faucault's (1997) plurality of values are designed to recapture, reconstruct and reinterpret past forms of human experience in order to better understand the present, pragmatic understanding of subjective constitution. This is rooted in everyday experience and takes place in the will to self invention, creativity, and transformation. Call it a new way of refusing to be what we are.

This pragmatic behavior is an affirmation of a new type of freedom, one which leaves behind the Cartesian ego as the foundation of all knowledge and replenishes human activity with a sense of non-discursive and practical creativity. Finding meaningful, purposeful experience based on practical and intellectual beliefs. The act of knowing is caught up in the quest for certainty. This opens the person who would seek freedom in a different type of employment, like the NGO, to seek continuous inquiry into the forces that have constituted us as subjects so that one day, we will look back and see the arbitrariness of scientific and humanist conceptions, placing primacy on experiential rather than epistemological foundations. We self-create through everyday practices and employ a pragmatic approach to our self existence. We must define the objects, rules of action, and odes of relation to ourselves if we are to analyze questions of general import. This is how a subject gets through to the pragmatic dimension. The Greeks would have called this epmemeia heautou, which is a term meaning the attainment of knowledge about oneself through thought and through practical experience. The connection to the late modern era rests on hope for subjects who are no longer passive dupes in the humanist regimes for power and knowledge but are attributed a degree of creativity within such regimes. The self is first and foremost a product of social life and the choice for occupation rests not in organizational society, but in the self will. Alliances shift in order from organization - profession - person to person - profession - organization. The point is to free on-oneself from power relations by acting ethically, by respecting one-self and acting in concert with others so as to maximize freedom. It is Faucault's (1997) view that when practices of individual freedom and collective liberation make themselves apparent can there be an opening up of the possibilities to pave the way for rationality and this freedom requires a certain degree of liberation to pave the way for new power relationships which must be controlled by the practices of freedom. To use William White's Organization Man (1938) one must think - what percentage of people were organizationally loyal twenty years' ago and what percentage has that attribute now?

\section{Viewpoints}

Let's look at some other viewpoints. Consider critical theory. Paradigms can be developed that can yield meaningful insights into phenomena not previously realized while combining them with existing paradigms in our quest for newer and better understanding. Recent efforts to create multi-paradigmatic approaches have proven interesting, and have caught some attention and created challenging viewpoints that can be useful beyond Faucault's view (Faucault, 1997; Wilber 1982; Hassard, 1988, 1993; Pfeffer, 1993; Van Maanan, 1994; Weaver and Gioia, 1994; Gioia, 1999; and Lynham, 2000). For instance, Wilber (1982) in "Physics, Mysticism, and the New Holographic Paradigm", characterizes organizations as holographic processes of transparency and the management of these organizations as taking place from all directions. This was an attempt to commensurate organizational paradigms to a holographic process. In response, Hassard and Parker $(1993,1998)$ called for multiparadigm research instead of Wilber's one holographic paradigm. Hassard is invoking an epistemological debate about whether it is possible to translate the meaning of one technical language (like physics) into another given that major theoretical paradigms are incommensurable.

Meaning given to the term "methodology" in social theory and management has its emphasis on procedures for gaining knowledge and on the scientist's identification and justification of findings. In management, the emphasis is on systematically understanding, predicting, and changing variables in the world with the ultimate aim being to promote the survival and growth of those organizations that through their output have distinctive competencies, compared to other organizations, in producing outputs that serve society. One might argue that management uses functionalist approaches to intervene in business enterprises in order to provide direction, competitive advantage, and 
competitive success, while operating in a logical or strategic direction. While these emphases can be criticized as one sided and misleading for their short sidedness, it could be held that these fields offer a great deal more understanding through strategic, political or cultural levels, however meanings ascribed to the idea of methodology in the social sciences and in management, particularly in the management of NGO type organizations, seem to be rather fuzzy given the current paradigms available. Methodology in the social sciences usually refers to the procedures used by a theorist in seeking to find out about social reality. In describing a particular methodology, reference will be made to theoretical assumptions adopted in that methodology. For example, one could describe the steps in social methodology and the theory underneath. In management, "methodology" is used to refer to methods for exploring and gaining knowledge about strategic content and process issues. Because management has a practical orientation, a normal usage for the word "methodology" is to describe the organized set of methods a theorist employs either to intervene in a real world strategic problem, or to pursue some course of study in the lab or in the field.

The two ways in which "methodology" are used in the social sciences and in NGO population, membership and management (PMM) suggest a different emphasis that is not entirely incommensurable. Surely there can be pragmatic application of an academic natural world and practical application to charitable human endeavors. The emphasis may be more on a pragmatic application in NGO PMM although there are similar theoretic applications in both the social sciences and NGO PMM that may cause one to think there is room for commensuration. The social sciences are strong on theory, they are strong on asking definitional questions, and they are strong on delving into the philosophies and assumptions of theorists in a desire to push the edge of knowledge, but not necessarily application of material. As an applied field, informed management asks questions regarding how to apply knowledge while teaching businesses, and by extension, NGOs how to achieve advantage and superior productivity. In NGO PMM, it is obvious that theoretical suppositions guide methodology to be used for intervention in business situations. Social science rarely, outside of the practical world, makes an effort to intervene in social reality in an effort to change it. Business scholars are dedicated to practice, but do not have well developed paradigms and theory. Any attempts to change the world rest upon created theoretical arguments about the nature of the world. In not having well created background for intervention, the strategic theorist will not take full advantage of opportunities to develop paradigms and learn from practice in order to develop the theoretical discipline.

There is potential for immense collaboration between social theory and management research in NGOs. Both fields can stand to gain if they can learn to think in terms of a complex and systematic view of methodology, and to strive to understand the complex meanings of social science and operations. What must happen here, is the creation of a set of theoretically grounded suppositions, followed by ability to intervene and plan.

\section{Paradigm Considerations}

Social science theory can help NGO PMM methods to be explored at a number of levels. At one level is the sociological orientation of Burrell and Morgan (1979) and the potential impact on NGO research and management theory. At an organizational level, Burrell and Morgan present key metaphors to steer the way researchers study and address questions of academic or practical importance. Finally, the issues of modernism and postmodernism are addressed.

\subsection{Knowledge and interest in social evolution}

As transient organizations (Yanacopoulos, 1998), NGOs are likely to require the technical and practical interest with a humanistic mission, where practicality takes on a new and more humanistic form.

For NGO PMM scholars seeking to intervene in organizations and social entities, organizations have subsystems that are concerned with production and with "steering" organizational direction. Management methods will be needed to be grounded in all three interests for their functioning. They might usefully be classified according to whether they can guide instrumental action oriented to the development of production, development of steering capacity, or communication action interested in the creation of understanding free from domination. From a critical perspective, it is important to check that NGO PMM methodologies support the technical interest, and are reflective in their own limitation, recognizing the proper sphere of applicability. Methods that serve the practical interest, and facilitate debate about purpose must attend to the possibility that systematically distorted communication may jeopardize the emergence of shared purpose and direction.

\subsection{Sociological paradigms and NGO PMM}

Many management theories really do resemble social theories, although many are drawn from the social sciences. They attempt to create principles of method for strategic researchers to follow when they seek to learn about and intervene. Principles we adopt for intervention must contain assumptions about how we can and should learn about reality and about the nature of that reality. This is true whether that reality is stated explicitly or whether it remains covert. One "useful" working tool that can enable us to unearth NGO PMM methodologies may be Burrell and 
Morgan's (1979) sociological paradigms for organizations. Within the framework, in Figure 1, the four paradigms are labeled "functionalist", "interpretive", "radical humanist" or "radical structuralism". Our concept of "Pragmatic Humanism" (Reynolds, 2004; Faucault, 1997; Rorty, 1989; 1999; Shusterman, 2001) is added on top to highlight the idea of individual action on top of epistemological structures, representing the desire for self determination, which is one basic reason for NGO PMM. Please see Figure 1.

\subsection{Interpretivism}

The interpretive paradigm, is based upon the view that the social world has a very precarious status, and that what passes as social reality does not exist in any concrete sense, but is the product of the subjective experience of individuals. Society is understood from the standpoint of the participant in action and the theorist attempts to understand the process through which shared realities arise and are sustained. Like the functionalist, the interpretive approach is based on the assumption and belief that there is an underlying pattern and order within the social world and the interpretive theorist views the functionalist's attempt to establish an objective social science as a desired end. Common viewpoints in interpretivism are that management and NGO PMM is a Hermeneutic game with ethnomethodology and interactionism.

\subsection{Radical Humanism}

The radical humanist paradigm, like the interpretive paradigm, emphasizes how reality is socially created and sustained but ties analysis to an interest in what may be described as the pathology of consciousness. Here, people become members of an habitual domain that lies within the bounds of the reality they create. This perspective is based on the view that the reality creation is influenced by psychic and social processes which channel, constrain, and control the minds of human beings, in ways which tie them only to their created interests. Capitalism, for example, is viewed as essentially totalitarian, the idea of capital accumulation molding the nature of work, technology, rationality, logic, science, roles, language and mystifying ideological concepts such as work, leisure. These concepts, which the functionalist theorist may regard as the building blocks of social order and human freedom stand, for the radical humanist, as modes of ideological dogma. Common viewpoints of radical humanism in NGO PMM and management are that it organizations are a psychic prison. This is the closest to our viewpoint of pragmatic humanism, however radical humanism operates within organizations and not extraorganizationally per se (Aktouf, 1990, 1992).

\subsection{Radical Structuralism}

The reality defined by the radical structuralist paradigm is predicated upon a view of society as a potentially dominating force. However, it is tied to a materialist conception of the social world, which is defined by hard, concrete, real structures. Reality is seen as existing on its own account independently of the way in which it is perceived and reaffirmed by people in everyday activities. Emphasis is placed upon the importance of praxis as a means of transcending this domination. Each of these four paradigms defines the grounds of opposing modes of social analysis and has radically different implications for the study of organizations. Here organizations are instruments of domination and schismatic.

\subsection{Functionalism}

The functionalist sector is based upon the assumption that society has a systematic character oriented to produce an ordered and regulated state of affairs. It encourages an approach to management that focuses upon understanding the role of everything in operations. For instance, persons' behavior is always seen as being contextually bound in a world of concrete and tangible social relationships. This encourages the Weberian belief in the possibility of an objective and value-free operation in which an organization, like an NGO, is distanced from the scene being addressed (Ritchie, 1994). This perspective is primarily regulative and pragmatic in its basic orientation, concerned with understanding society in a way which generates strategic decisions in a rational world. Finally, the functionalist paradigm sees organization as social systems, machines, cybernetic systems, organisms, cultures, and bound to determinism, pluralism, and an action frame of reference. This is the opposite of what radical humanism and pragmatic humanism would describe (Demerath, 1996).

\section{Paradigm Collaboration}

It should be obvious that our understanding of NGO PMM has a great deal to gain from collaboration and awareness of social theory. While arguments have been made to enfold economics into management, perhaps a more interesting "friend" can be found in the social sciences. Considerable insight can be found from delving into individual methodologies. Similar analyses can be performed on any paradigm or economic methodology, like transaction costs analysis, or agency theory. Just as Jackson (1993) has done for all strains of "enhanced" operations analysis, a scholar in Images of Organization could do the same for Modernism. The traditional approach to NGO interests serves the 
technical interest, is based upon functionalism, gives credence to the various metaphors, and is systemic modernist in orientation.

Social theory can bring increased understanding to individual methodology. Social theory has much to offer management as a field. The main points that could be made can be summarized as:

1) Support for complementarism between management of NGOs and their environments.

2) Support for methodology choice in the muddled field.

3) Enabling NGO PMM to be taught in the appropriate discipline, which this paper would argue is a hybridized for of public or non-profit management.

4) Improving the methodologies and techniques available from policy oriented material to more functional choices. Different philosophical and sociological assumptions relied upon by the various approach serves different objectives. The question: are they a complementary set or are they in conflict in some way is an important one. The argument that management is within a paradigm crisis in which a variety of approaches opposed on fundamental matters concerning the nature and purposes of a discipline compete with one another has been put forward by Pfeffer (1993) and by Dando and Bennett (1982). It rests on the notion of Paradigm incommensurability, favored by Kuhn (1970); by Dando and Bennett (1982); by Pfeffer (1993); and by Burrell and Morgan (1979). Instead of setting up different strands of NGO PMM as competing for the same area of concern, alternative approaches can be presented as being appropriate to the different types of situation in which strategic managers are required to act. Each approach will be useful in certain defined areas and should be used in the circumstances where it works best. If this perspective is adopted, then the diversity of approaches heralds not a crisis, but increased competence and effectiveness in a variety of situations, especially in terms of academic field legitimacy. Once complementarism is accepted, rather than one paradigm over another, then the kind of analysis of strategic managers makes it possible to determine the relative strengths and weaknesses of differing approaches.

The understanding of the presuppositions of different managerial approaches makes it possible to use theory from the social sciences to help with important questions being faced by researchers interested in this organizational for. This question is which theories are best? It becomes possible to ask whether the assumptions made can be identified in the world, and whether their objectives are agreed upon by all participants. The social consequences of using a particular strategic methodology are opened by social theory.

It is well known there are problems of understanding NGO PMM both domestic to North America as well as in more international climates. Managerial approaches should not be regarded as fixed in stone; they develop over time in response to theoretical and methodological innovation and as a result of reflection on practice. No doubt the field could benefit from refinements which could be made by viewing them from a social theory perspective. The assumptions each makes are also tested out in every intervention, in the "real world". Considering interventions in the light of extra knowledge that social theory can bring, should be beneficial.

\section{Conclusions and Extensions}

The matter of NGO PMM and social sciences theory benefitting NGO PMM and NGO PMM fitting social science theory is considered in this paper. It is the opinion in this paper that the images of functionalism and modernism should be replaced not by radical humanism or structuralism, but by a practical humanism that views the human being as central to the effort and should be considered in light of the existing theory but also in light of the concept of practicality with notation to the efforts and needs of humans in the endeavor (Eisenhardt, 1991). This may be the reason so many people are leaving the corporate and academic world for the human service of the NGO. The psychological rewards are better as are the outcomes and flexibility in conceptualizing the structure and patterns of work in functionalist as well as humanistic terms. In this regard, the relevance of social theory courses could be made more explicit. We might say that with the consideration of the paradigms in the images of organization and the modernism debate, permutated into the practical humanism we espouse the prize to offer NGO managers social scientists and management practitioners is in the understanding, and prediction of operational success. Call it a Paradigm found. The phronesis, or practical reason that is informed by multi-paradigm consideration gives us an insight in operations, but also into the human conditions that make this type of organizational form work.

\section{References}

Aktouf, O. (1992). Management and theories of organizations in the 1990s: Toward a critical radical humanism. Academy of Management Review, $18: 3$ (July, 1992), p. 407-431.

Aktouf, O. (1996). Traditional Management and Beyond. (Montreal: Morin).

Burrell, G. and Morgan, G. (1979). Sociological Paradigms and Organizational Analysis. (London: Heinemann).

Dando, M.R., and Bennett P.G., (1981). A Kuhnian crisis in management science? The Journal of the Operational 
Research Society, 32:2 p. 91-103.

Demerath, N.J. (1996). Who Now Debates Functionalism? From "System, Change and Conflict" to "Culture, Choice, and Praxis Sociological Forum, 11:2 p. 333-345.

Eisenhardt, K. (1991). Better stories and better constructs: The case for rigor and comparative logic. The Academy of Management Review, 16:3 p. 620-627.

Fowler, A. (1992). Distant Obligations: Speculations on NGO Funding and the Global Market.

Review of African Political Economy, No. 55, p. 9-29.

Gioia, D. (1999). Gioia's reply to Jones and Wicks. The Academy of Management Review, 24:4 p. 624-625.

Gioia, D. (1999). Response: Practicability, paradigms, and problems in stakeholder theorizing. The Academy of Management Review, 24:2 p.228-232.

Gioia, D., M Schultz, K. Corley. (2000). Organizational identity, image, and adaptive instability. The Academy of Management Review, 25:1 p. 63-81.

Guinn, D.E. (2008). Defining the Problem of Trafficking: The Interplay of US Law, Donor, and NGO Engagement and the Local Context in Latin America. Human Rights Quarterly, 30:1 p. 119-145.

Hassard, J., and Holliday, R. (1998). Organization-representation: Work and organization in popular culture. (1000 Oaks, CA: Sage Publications).

Hassard, J. and M. Parker. (1993). Postmodernism and Organizations. (London: Sage).

Kim, E. (2009). The Limits of NGO-Government Relations in South Korea.

Asian Survey, 49:5 p. 873-894.

Kuhn. (1970). The Structure of Scientific Revolutions (Chicago: University of Chicago Press).

Pfeffer, J. (1993) Barriers to the advance of organizational science: Paradigm development as a dependent variable. Academy of Management Review, 18:4, p. 599-620.

Lynham, S.A. (2000). Theory building in the human resource development profession. Human resource Development Quarterly, 11:2 p.159-169.

Lyotard, J.F. (1984) .The Postmodern Condition. (Minneapolis: The University of Minneapolis Press).

Morgan, G. (1980). Paradigms, metaphors, and puzzle solving in organizational theory. Administrative Science Quarterly, 25:4 p. 605-622.

Morgan G. (1983) More on metaphor: Why we cannot control tropes in administrative science. Administrative Science Quarterly, 28:4 (Dec., 1983) pp. 601-607.

Reynolds, J.M. (2004). Pragmatic Humanism in Foucault's later work. Canadian Journal of Political Science / Revue Canadienne de science politique. 37:4 p. 951 - 977.

Ritchie, C. (1995). Coordinate? Cooperate? Harmonise? NGO Policy and Operational Coalitions. Third World Quarterly, Vol. 16, No. 3, p. 513-524.

Rorty, R. (1989). Contingency, Irony, and Solidarity (Cambridge: Cambridge University Press).

Rorty, R. (1999). Hope in Place of Knowledge: A Version of Pragmatism (Cambridge: Cambridge University Press).

Teegen, H., Doh, J. and Vachani, S. (2004). The importance of nongovernmental organizations in global governance and value creation: An international business research agenda. Journal of International Business

Thomas, J.T., S. Clark, D. Gioia. (1993). Strategic sensemaking and organizational performance: Linkages among scanning, interpretation, action, and outcomes. The Academy of Management Journal, 36:2 p. 239-270.

Uvjn, P., Jain, P., and Brown, D. (2000). Think large and act small: Toward a new pardadigm for NGO scaling up. World Development 2000.

Wilber, K. (ed). (1982). The Holographic Paradigm and Other Paradoxes. (Boulder, Co.: Shambhala).

Williamson, O. (1998) .Transaction cost economics: how it works; and where it is headed. De Economist, 146:1 p. $23-58$.

Yanacopulos, H. (2005). The strategies that bind: NGO coalitions and their influence. Global Networks (Cambridge: Cambridge University Press).

Vol 5, p.193 - 200 . 
Yarrow, T. (2008). "Life/History: Personal Narratives of Development Amongst Ngo Workers and Activists in Ghana." Africa: Journal of the International African Institute, Vol. 78, No. 3 (2008), pp. 334-358.

\begin{tabular}{|c|c|c|}
\hline SUBJECTIVE & THE SOCIOLO & RADICAL C \\
\hline ( & $\begin{array}{l}\text { RADICAL } \\
\text { HUMANISM } \\
\text { (Radical change throwing off } \\
\text { bounds of exploitation.) }\end{array}$ & $\begin{array}{r}\text { RA } \\
\text { STRUC } \\
\text { (Structural ch } \\
\text { free humankir }\end{array}$ \\
\hline & $\begin{array}{r}\mathbf{P} \\
\mathbf{F} \\
\text { (Worth } \mathrm{c} \\
\text { determi } \\
\mathrm{b}\end{array}$ & $\begin{array}{l}\text { IATIC } \\
\text { NISM } \\
\text { person to self } \\
\text { rding to own } \\
\text { rests.) }\end{array}$ \\
\hline & $\begin{array}{l}\text { (Contingent management of } \\
\text { situations.) } \\
\text { INTERPRETIVE }\end{array}$ & $\begin{array}{l}\text { (Rationality, } p \\
\text { management } \\
\text { strategy.) } \\
\text { FUNC }\end{array}$ \\
\hline
\end{tabular}

THE SOCIOLOGY OF REGULATION

Figure 1. 